\title{
Constitución de Identidad, Constitución de Humanidad desde Nuestra América
}

\section{Constitution Of Identity And Humanity Of}

Our Constitution From America

Constituição De Identidade E Constituição De

Humanidade Da Nossa América
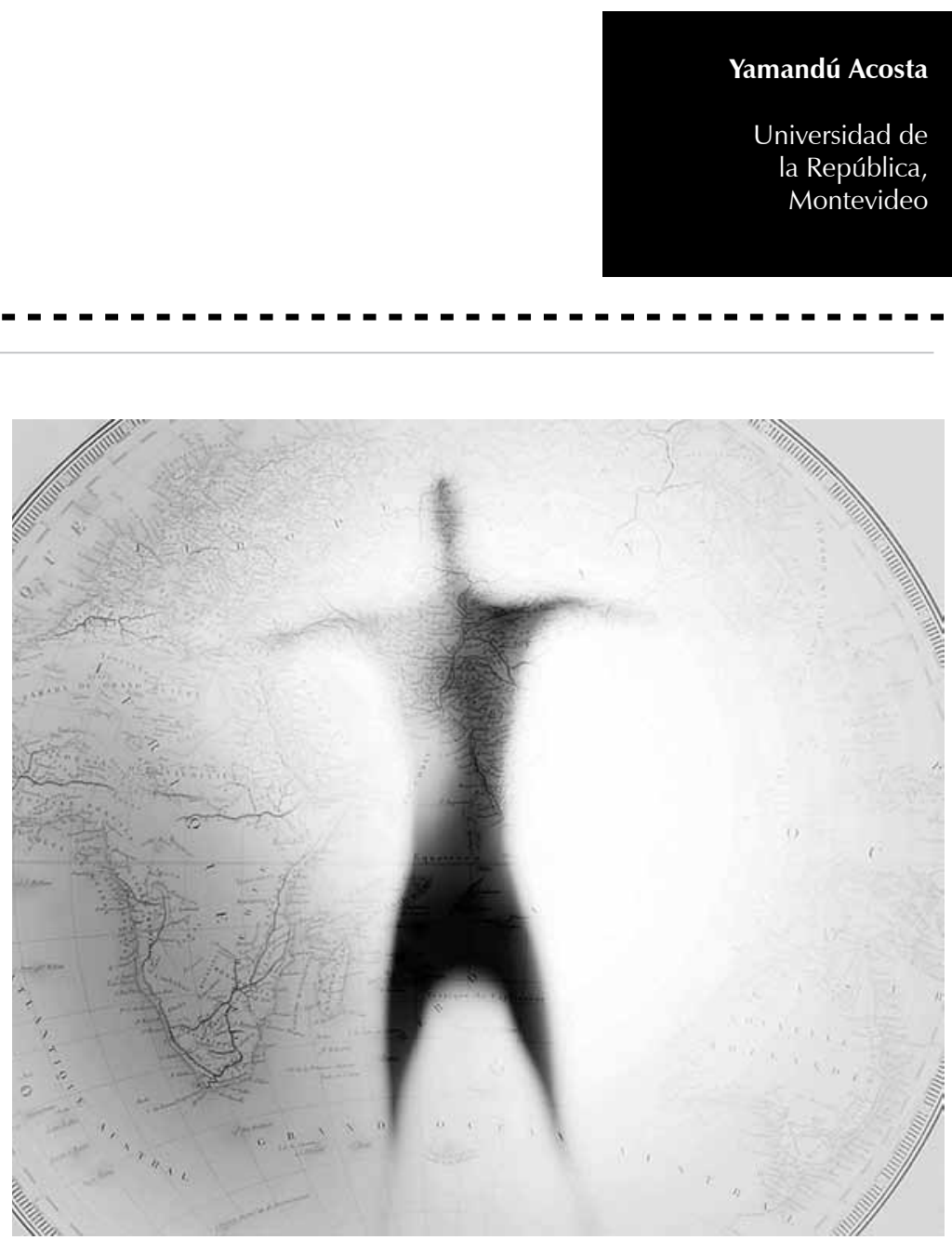
Resumo: O artigo considera a nossaAmérica como lócus de constituição de identidade e humanidade. O assunto da identidadelatino-americana da psicologia - implicado na anterior - éconvocado nas considerações das implicações no contraste das perspectivas do Novo Mundo e da nossa América, nas quais pode ele pode ser articulado. A partir do discernimento entreidentidades autênticas e identificações inerciais, é levada em consideração adialética de projetos que definiram as principais linhas sobre a constituiçãode identidade e de humanidade na América Latina. Finalmente, é considerado o a priori antropológico na constituição de identidades autênticas e deprocessos de autoconhecimento e reconhecimento na nossa América que formam aconstituição da humanidade.

Palavras-chave: Identidade. Psicologia. Humanidade. Nossa America.

Abstract: The article considers our America as a constitution of identity and humanity locus. The subject of the Latin American identity of psychology-implied in the preceding - is summoned in the considerations of theimplications in the contrast of the New World and our America perspectives, inwhich it can be articulated. From the discernment among authentic identities and inertialidentifications, the dialectic of projects that defined the principal lines onidentity and humanity constitution in Latin America is considered. Finally it is considered the anthropological a priori in theconstitution of authentic identities and of self-knowledge and the process ofrecognition in our America, what makes the Humanity constitution itself.

Keywords: Identity. Psichology. Humanity. OurAmerica.

Resumen: El artículo considera a nuestra América como locus deconstitución de identidad y de humanidad. El tema de la identidad latinoamericana de la psicología- implicada en la anterior - es convocado en las consideracionesde las implicaciones en el contraste de las perspectivas del Nuevo Mundo y denuestra América, en las cuales puede articularse. Desde el discernimiento entre identidades auténticas eidentificaciones inerciales, se tiene en cuenta la dialéctica de proyectos que definieronlas principales líneas sobre la constitución de identidad y de humanidad en Latinoamérica. Se considera, finalmente, el a priori antropológicoen la constitución de identidades auténticas y de procesos de autoconocimientoy reconocimiento en nuestra América que forman la constitución de humanidad.

Palavras-clave: Identidad. Psicología. Humanidad. Nuestra América.

La Unión Latinoamericana de Psicología (ULAPSI) ha convocado a debatir en torno a "La identidad latinoamericana de la Psicología" y su Presidente, el Prof. Psicólogo Carlos Lesino, con quien me une una larga amistad que el tiempo no ha hecho sino fortalecer, en conocimiento de mi también larga dedicación a la filosofía latinoamericana, me ha distinguido invitándome a exponer en la jornada de cierre de la actividad convocada -lo que agradezco tanto en su carácter de señal de amistad como de reconocimiento a mi trayectoria de investigación y reflexiónponiéndome frente al desafío de aportar una exposición que pueda ser pertinente al eje problemático de referencia de las exposiciones y debates de los tres días transcurridos.

La ubicación en la instancia de clausura del evento de un expositor que tiene en la filosofía su matriz disciplinaria de origen aunque desde ella se haya abierto cada vez más a la multidisciplina, la interdisciplina, la transdisciplina y en definitiva, la indisciplina-, podría tal vez responder a la lectura hegeliana del lugar de la filosofía que se ofrece en el Prefacio a la Filosofía del Derecho fechado en Berlín el 25 de junio de 1820, en el que se enuncia "Cuando la filosofía pinta el claroscuro, ya un aspecto de las vida ha envejecido y en la penumbra no se la puede rejuvenecer, sino sólo reconocer: el búho de Minerva inicia su vuelo al caer el crepúsculo" (Hegel, 1968, p.37).

No obstante, se trata en este caso de la filosofía latinoamericana, que en relación a Hegel, más allá de él y contra él, se constituye como un "filosofar matutino o auroral, (que) confiere al sujeto una participación creadora y transformadora, en cuanto que la filosofía no es ejercida como una función justificatoria de un pasado, sino de denuncia de un presente y anuncio de un futuro, abiertos a la alteridad como factor de real presencia dentro del 
1La palabra introducida entre paréntesis es nuestra.

2 Expresa Kant en la "Lógica Trascendental", bajo el título "De la lógica en general":

"Pensamientos sin contenido son vacíos; intuiciones sin conceptos son ciegas"

(1967, Tomo I, p. 202).

3Carlos Marx: "Pero las fuerzas productivas que se desarrollan en el seno de la sociedad burguesa brindan, al mismo tiempo, las condiciones materiales para la solución de este antagonismo. Con esta formación social se cierra, por tanto, la prehistoria de la sociedad humana" (1955, Tomo I, pp.241-242).

4 Por "sujetividad" se entiende aquí con Arturo Andrés Roig, la "afirmación del sujeto" a través de la "exigencia fundante" de "ponernos para nosotros y valer sencillamente para nosotros" en que el ejercicio del a priori antropológico que funda la constitución del sujeto -que es constitución de identidad- consiste. proceso histórico de las relaciones humanas" (Roig, 1981, p. 15) ${ }^{1}$.

A través de la exposición en que comenzamos a introducirnos, se procura acompañar la iniciativa de "la construcción de la identidad latinoamericana de la psicología". Ésta, pienso, supone de modo propio desde América Latina, denuncia de este presente y anuncio de un futuro "abiertos a la alteridad como factor de real presencia dentro del proceso histórico de las relaciones humanas" , orientación de sentido teórico-prácticoestratégico-táctico sobre la que se ha venido muy probablemente debatiendo, que resignifica a esta clausura en apertura hacia el horizonte de lo que debe ser porque puede ser y es valioso que sea en lo que a la identidad de la psicología en América Latina se refiere.

Ese pretendido acompañamiento consistirá en reflexionar sobre la constitución de la identidad en sus relaciones con la constitución de la humanidad desde Nuestra América.

Se suponen conflictivos y nunca acabados los procesos de constitución de identidad y por cierto los de constitución de humanidad, cuya relación se estima igualmente conflictiva así como inevitable. Parafraseando a Kant nos permitimos postular: constitución de humanidad sin constitución de identidad es ciega y constitución de identidad sin constitución de humanidad es vacía².

La constitución de identidad es una mediación histórica -también psicológica- para la constitución de humanidad desde que la posibilidad de constitución de la humanidad no está dada directamente sino a través de diversas mediaciones. Más aún, lejos de haber ingresado propiamente en la historia humana en el marco de la sociedad hoy globalmente existente, se ha argumentado que nos encontraríamos tal vez apenas en "la prehistoria de la sociedad humana"3.
Nuestra América, como locus de constitución de identidad y humanidad tiene una doble dimensión tópica y utópica que en "Nuestra América" de José Martí de 1891 encuentra un fundamental referente discursivo en relación al cual potenciar la función utópica del discurso que al hacer a la constitución de "sujetividad"4, lo hace a la de la identidad y a la de la humanidad.

\section{Nuestra América como locus de constitución de identidad y de humanidad}

Usar la expresión "nuestra América" para referirnos a la región geo-histórico-cultural que habitualmente llamamos América Latina o Latinoamérica, no obstante presentar algunos inconvenientes, presenta comparativamente algunas ventajas.

Sin intencionalidad de hacerlo, "Latinoamérica" o "América Latina" que continúan teniendo valor de convocatoria en términos de unidad e integración hacia el interior de esta América y de correspondiente separación de la otra América, la del norte, la América sajona; implican en términos de construcción de identidad y por tanto de humanidad la invisibilización de lo indoamericano y lo afroamericano, componentes centrales de la identidad y la humanidad en esta América.

Por su parte, "nuestra América" implica la referencia a un "nosotros". Un "nosotros" tópico en proceso de constitución que es heterogéneo, diverso, conflictivo y profundamente inequitativo que encuentra en un "nosotros" utópico heterogéneo, diverso, conflictivo pero profundamente igualitario y fraterno el referente trascendental o idea crítico-reguladora para transformar el "nosotros" vigente y superar sus inequidades en la perspectiva de una constitución de identidad, la de "nosotros" los "nuestroamericanos" que sea un aporte en la constitución de humanidad 
5 Entre 2001 en que se cumplían los ciento diez años de publicación del ensayo de Martí y 2011 en que se cumplieron los ciento veinte años de ese hecho, hemos escrito, presentado en distintos foros y eventualmente publicado una serie de textos que hemos reunido en el libro Reflexiones desde "Nuestra América". Estudios latinoamericanos de filosofía de la práctica e historia de las ideas, de próxima publicación, desde y para nosotros y también para los otros, los de la otra América y demás identidades geo-histórico-culturales del mundo, inclusión de la diversidad que es condición para la constitución de la universalidad de lo humano.

Como adelantamos en nuestra introducción a esta exposición, "Nuestra América" de José Martí, de cuya primera publicación en La Revista Ilustrada de Nueva York el 1 de enero de 1891 -simbólica y paradójicamente en la otra América- se cumplieron en 2011, ciento veinte años, aporta de un modo sustantivo, válido y vigente desde el punto de vista analítico-crítico-normativo a esta conflictiva y nunca acabada constitución de identidad y de humanidad, por lo que las orientaciones que en ella aparecen estarán presentes en nuestro actual desarrollo, aunque declinaremos de la tentación de reflexionar una vez más centralmente ${ }^{5}$ sobre ese texto-manifiesto filosófico, cultural y político que como clásico es relevante interlocutor del presente.

\section{La identidad latinoamericana de la psicología: entre el Nuevo Mundo y Nuestra América}

Sin temor a equivocarme puedo decir que el de la "identidad", asunto sobre el que la convocatoria que hoy nos reúne, no es un simple "tema" aleatoriamente seleccionado entre otros muchos posibles para un congreso de psicología, sino que tiene el rango de "problema", y más estrictamente, de problema filosófico auténtico. Abonando esta tesis, señalaba Mario Sambarino en Morelia, Michoacán, México, en 1975 al reflexionar sobre la función socio-cultural de la filosofía en América Latina: "un problema filosófico es auténtico cuando se encuentra situado en relación con la problemática radical de una configuración socio-cultural" (Sambarino, 1976, pp. 171-172).
El de la "identidad" es un problema filosófico auténtico en tanto se encuentra situado en relación con la problemática radical de nuestra configuración socio-cultural "nuestroamericana", así como por inclusión lo es el de la identidad de la psicología por lo que implica epistemológicamente en los fundamentos de la propia disciplina y en sus proyecciones prácticas a la constitución de la conflictiva y nunca acabada constitución de aquella identidad de la que forma parte, al aportar, sea a la constitución de identidades, sea a la constitución de identificaciones inerciales que usurpan el lugar de las identidades auténticas.

Para la elucidación del problema de "la identidad latinoamericana de la psicología" entiendo como válida y vigente la hipótesis con la que el filósofo chileno José SantosHerceg en su magnífico libro Conflicto de representaciones. América Latina como lugar para la filosofía (Santos-Herceg, 2010), organiza su estudio crítico de la filosofía en América Latina, discerniendo entre "Filosofía en el Nuevo Mundo" (pp. 31-147) y "Filosofar en Nuestra América" (pp. 149-262) para concluir en la perspectiva de la "Filosofía en La Tempestad" (pp. 263-277).

La pregunta a la que el libro de José Santos responde es a la de la identidad latinoamericana de la filosofía. Para ello procedió desde la elucidación del lugar de la filosofía al sujeto de la misma para retornar del sujeto al lugar. En cuanto al lugar, "América Latina", encontró que compiten una multitud de representaciones, entre ellas, las del "Nuevo Mundo" y de "Nuestra América" le parecieron las más "extremas" y "antagónicas", entendiendo que "al comenzar con la exacerbación de las diferencias se pondría más en evidencia la hipótesis: una cosa es la filosofía en el Nuevo Mundo y otra muy diferente la filosofía de Nuestra América" (Santos-Herceg, 2010, p. 264). 
En efecto:

América Latina en tanto que Nuevo Mundo es un lugar que fue soñado, luego inventado, invadido, conquistado, dominado y colonizado, por los españoles primero, pero por otros después de ellos. América Latina en tanto que Nuestra América es, por su parte una tierra desconocida, llagada por el sufrimiento y la muerte; es el sueño de la unidad pero sobre todo es reacción al dolor, resistencia a la dominación, lucha por la autonomía y la independencia. Diferentes representaciones de América Latina: dos lugares en uno" (Santos-Herceg, 2010, p. 264)

Estas diferentes representaciones desde las cuales se desarrolla el pensamiento filosófico motivan identidades contrapuestas de la filosofía en América Latina:

La que surge en el Nuevo Mundo, en tanto que se trata de un lugar conquistado, dominado y colonizado, es una reflexión colonizadora, por una parte, y colonizada por otra. Aquella que nace en Nuestra América, por el contrario en tanto que aparece en el lugar de la amenaza y el dolor, pero también de la resistencia y sueño de liberación, es una reflexión que busca reaccionar, resistir en vistas de la emancipación: es una filosofía liberadora y que persigue liberarse" (Santos-Herceg, 2010, p. 264)

¿No será el caso de que la psicología en América Latina se ha desarrollado fundamentalmente en la lógica de la representación del Nuevo Mundo en la cual estaría implicada una identidad colonizada y colonizadora de su ejercicio que la harían funcional a la reproducción de la identidad colonizada y colonizadora de la porción de humanidad a cuya salud procura contribuir?

¿No estaremos justamente posicionándonos críticamente frente a esa orientación hasta hoy dominante, procurando para la psicología y sus efectos de realidad sobre la salud de la población a la que el ejercicio de aquella apunta a contribuir una identidad "liberadora y que persigue liberarse"?
¿No estará en juego en este discernimiento el del concepto mismo de salud en su dimensión psicológica tanto individual como social?

Parafraseando a José Santos, pero atendiendo a la identidad latinoamericana de la psicología como problema, nos permitimos sospechar que tal vez no existe "el" modo de ser de la psicología en América Latina, "sino que se pueden distinguir diferentes modalidades de acuerdo con el "lugar" en que" (SantosHerceg, 2010, p.264) la psicología o -mejor aún- su sujeto se sitúe, esto es "de acuerdo con su "lugar de enunciación" (SantosHerceg, 2010, p. 264).

Asumiendo los riesgos de una "simplificación burda" como los que asume José Santos para discernir la efectiva identidad de la filosofía en América Latina, nos permitimos trascendentalizar para el problema de la identidad de la psicología "tres arquetipos de filósofos" que a su juicio "se pueden rastrear con nitidez" y que para nuestra pregunta referiría a tres arquetipos de psicólogos en Latinoamérica (Santos-Herceg, 2010, p. 264).

Esos tres arquetipos de la filosofía, trascendentalizados como arquetipos de la psicología en América Latina, aparecen simbólicamente representados en la figuras de Próspero, Ariel y Calibán a partir de una nueva revisita de La tempestad de William Shakespeare, que ha sido ya objeto de diversas revisitas desde América Latina, entre ellas las de José Enrique Rodó en su Ariel de 1900, la de Aníbal Ponce en su Humanismo burgués y humanismo proletario de 1935 y la de Roberto Fernández Retamar en su Calibán de 1971.

En atención a la misma obra de Shakespeare, Próspero de acuerdo a la lectura de José Santos "sirve como arquetipo del filósofo del poder, de la dominación" (Santos-Herceg, 2010, p. 266), acompañando a la cual serviría para nosotros hoy como arquetipo 
6 El texto entre guiones es nuestro.

7 Fragmento de Ariel de Rodó, citado por SantosHerceg.

8 Sánchez, C. (2005). Escenas del cuerpo escindido. Ensayos cruzados de filosofía, literatura y arte. I Chile: escenas de la filosofía, el cuerpo mórbido, género y perfomance. (p. 29) Santiago, Chile: Arcis/ Cuerpo Propio citado por Santos-Herceg.

9 Escribe Hobbes en su obra Leviatán de 1651: "la sabiduría se adquiere, no leyendo libros, sino leyendo hombres". (Hobbes, 1994, p.14.) del psicólogo -y por lo tanto de la psicologíadel poder, de la dominación. "El filósofo / Próspero -interpreta Santos- utiliza su saber y sus conocimientos para conseguir el control, para dominar a otros, transformando su conocimiento en magia negra, en un saber que encadena, que limita y coarta". Sería, en clave de la identidad de la psicología en América Latina el arquetipo del psicólogo $-y$ la psicología- del poder, de la dominación.

No obstante, la lectura que de Próspero hace Rodó en su Ariel en la que lo coloca desde la percepción de sus discípulos en la condición de "viejo y venerado maestro", recupera el sentido del Próspero del final de la obra de Shakespeare, que como enfatiza Santos "destruye maleficios, arregla los entuertos, libera a Ariel, es una buena metáfora de este otro filósofo occidental -para nosotros ahora psicólogo occidental- cuyo objetivo no es la esclavitud sino la emancipación" (Santos-Herceg, 2010, p. 270) ${ }^{6}$. Dominación y emancipación estarían entonces en la lógica de constitución y proyección de la acción del psicólogo occidental simbolizado en la figura de Próspero.

El segundo arquetipo está simbolizado en la figura de Ariel. Repasa Santos la elaboración que del mismo hace José Enrique Rodó en la obra que lleva ese nombre y en donde lo caracteriza diciendo "Ariel es el imperio de la razón y el sentimiento sobre los bajos estímulos de la irracionalidad: es el entusiasmo generoso, el móvil alto y desinteresado en la acción, la espiritualidad de la cultura, la vivacidad de la gracia y la inteligencia, el término ideal a que asciende la selección humana, rectificando en el hombre superior los tenaces vestigios de Calibán" (Santos-Herceg, 2010, p. 270) ${ }^{7}$.

Luego comenta: "No es ningún secreto que Ariel ha servido de arquetipo del pensador latinoamericano. "Mezcla de esclavo y mercenario", como habría dicho Aníbal
Ponce. El filósofo en el Nuevo Mundo, en aquél lugar que ha sido conquistado y dominado, es un pensador colonizado. Aquél pensador que queda atrapado en/por una filosofía colonizada, que lo único que logra hacer es actuar con los designios del maestro" (Santos-Herceg, 2010, p. 272).

Poniendo al psicólogo en el lugar del pensador, Ariel sería el arquetipo del psicólogo latinoamericano, "mezcla de esclavo y mercenario" de acuerdo a la caracterización de Ponce, el psicólogo en el Nuevo Mundo, en aquél lugar que ha sido conquistado y dominado, es un psicólogo colonizado. Aquél psicólogo que queda atrapado en/por una psicología colonizada, que lo único que logra es actuar con los designios del maestro. De esta manera Ariel actúa con los designios de Próspero, el psicólogo latinoamericano en el Nuevo Mundo, cumple con los designios del psicólogo occidental en un ejercicio de la psicología en el que cohabitan el sentido de la dominación y el de la liberación.

El lugar del pensador latinoamericano en el preciso registro de "los pensadores de lámparas" (Martí, 2010, p. 15) a que se refería Martí en "Nuestra América" es el "despacho". Allí el pensador latinoamericano se "abstrae del mundo y de sí mismo. A medida que profundiza en sus lecturas, se despersonaliza e ingresa en el logos de filosofías ya dichas" (Santos-Herceg, 2010, p. 273$)^{8}$. "La universalidad de la filosofía nace allí. El despacho se vuelve una suerte de pasadizo al no-lugar de la filosofía" (SantosHerceg, 2010, p. 273).

¿Cabría la comparación entre el despacho del pensador latinoamericano en el registro de "los pensadores de lámparas" y el consultorio del psicólogo latinoamericano? ¿Podrá ser el consultorio un lugar en que el psicólogo latinoamericano se abstrae del mundo y de sí mismo y a medida en que profundiza en sus lecturas -que son de seres humanos ${ }^{9}$ pero 
por la mediación de lecturas de libros $^{10}$ - se despersonaliza e ingresa en el logos de psicologías ya dichas? ¿Será el consultorio el lugar en el que nace la universalidad de la psicología? ¿Así como el despacho del filósofo latinoamericano, podrá ser el consultorio del psicólogo del Nuevo Mundo el pasadizo al no lugar de la psicología? Todas estas preguntas se tornan razonables en la verosímil trascendentalización al campo de la psicología de Ariel como arquetipo del psicólogo latinoamericano cuyo lugar de enunciación parece no abandonar del todo el Nuevo Mundo, ni aspirar a situarse del todo desde Nuestra América.

El tercer arquetipo, Calibán, es el que al simbolizar al pensador latinoamericano que definitivamente hace de Nuestra América su lugar de enunciación, podría de acuerdo a nuestra pretensión de analogía hacerlo con el psicólogo latinoamericano como sujeto de una identidad latinoamericana de la psicología en el sentido de psicología "liberadora y que persigue liberarse" como propia de esta, Nuestra América.

Calibán es, como recuerda Roberto Fernández Retamar quien lo propone como "metáforasímbolo" de la cultura latinoamericana" (Santos-Herceg, 2010, p. 273), el que "aprende la lengua de Próspero y la utiliza para maldecirlo" (p. 274): "iMe habéis enseñado a hablar, y el provecho que se ha reportado es saber como maldecir! iQue caiga sobre vos la roja peste por haberme inculcado vuestro lenguaje! (...) iQue todas las miasmas que absorbe el sol de los pantanos, barrancas y aguas estancadas caigan sobre próspero y lo hagan morir a pedazos!" (p. 274) ${ }^{11}$.

"El filósofo/Calibán -comenta Santos- es el que -en términos de Fernández Retamarlogra "romper sus nexos de dependencia con la cultura metropolitana que le enseñó el lenguaje, el aparato conceptual y técnico. Ese lenguaje, en la terminología shakesperiana, le servirá para maldecir a Próspero" (SantosHerceg, 2010, p. 274) ${ }^{12}$.

En nuestra propuesta al arquetipo del filósofo/ Calibán corresponde la del psicólogo/Calibán quien logra romper sus nexos de dependencia con la psicología metropolitana que le enseñó el lenguaje, el aparato conceptual y técnico. Ese lenguaje que, ahora en el plano de la psicología, le servirá para maldecir a Próspero.

También Calibán, -señala Santos- con intención de fecundar a Miranda, la hija de Próspero para "multiplicarse en el mestizaje"(Santos-Herceg, 2010, p. 275), intenta violarla. Comenta Santos el sentido profundo de este intento:

\begin{abstract}
el filósofo/Calibán es el violador de las hijas de Occidente, de sus ideas, de su filosofía: se apropia de ellas, las toma quizás a la fuerza pues no han sido destinadas para él y busca preñarlas, busca engendrar pensamientos híbridos, nuevos. Ideas algo monstruosas para Occidente, por ser hijas de Calibán, el monstruo de los monstruos. Un engendro que no tiene salvación posible, condición que sus hijos, sean o no de Miranda, compartían (2010, p. 275)
\end{abstract}

¿No podrá ser el psicólogo/Calibán de Nuestra América el violador de las hijas de Occidente, de sus ideas, de su psicología, quien se apropia de ellas tomándolas quizás a la fuerza pues no han sido destinadas para él y procura preñarlas para engendrar conceptos y categorías de análisis híbridos, nuevos en el campo de la psicología? ¿Aceptará Occidente esos engendros o aplicará el argumentum ad hominem y por ser hijos de Calibán, monstruo de los monstruos, los descalificará como "maldecir" en cuanto "balbuceo" sin pertinencia teórica, en particular si además son hijos de la violación? ¿Qué pasará con el psicólogo/Ariel? ¿Hará suya la condena a la condena del psicólogo/Calibán y su psicología emergente por parte del psicólogo/ Próspero para permanecer al amparo de su 
universalidad, o tomará riesgo y se aventurará a dialogar las alternativas emergentes desde Nuestra América y a incluirlas con el criterio de pertinencia en su teoría y en su práctica?

Finalmente, nos recuerda José Santos atendiendo con detenimiento y rigor analítico e interpretativo a La tempestad, "El filósofo/Calibán es también, en algún sentido, el traidor que niega el legado europeo que se le ha ofrecido junto con el dolor de la conquista" (Santos-Herceg, 2010, p. 275). Agrega Santos sobre este sentido del Calibán de Shakespeare trascendentalizado a la filosofía desde Nuestra América:

Ese es el reproche de Calibán: maldice a Próspero por haberle enseñado a hablar. Lo maldice por su legado cultural y lo odia por ello, cerrándose a asumirlo como irreversible. Este filósofo/Calibán piensa que negando la tradición europeooccidental, matándola, logrará recuperar su lugar original y para ello tiende a recurrir a nuevos aliados, cayendo en nuevas dependencias. La experiencia es frustrante: lo único que consigue es una esclavitud aún más patética (Santos-Herceg, 2010, p. 276)

¿No se describe aquí el riesgo que podría correr el psicólogo/Calibán si se orientara a cometer parricidio en nombre de su liberación como psicólogo y de la liberación de, con y desde la psicología en Nuestra América, recurriendo para ello a nuevos aliados que podrían Ilevarlo a nuevas dependencias y a una esclavitud aún más patética? ¿No se vería arrastrado el psicólogo/Ariel a los efectos negativos no intencionales mencionados si acompañara sin discernimiento al psicólogo/Calibán en el crimen de parricidio en nombre de su liberación como psicólogo y de, con y desde la psicología en Nuestra América? ¿Deberá abandonar su consultorio en cuanto "pasadizo al no lugar de la psicología" o deberá transformarlo en lugar para la misma llenándolo con los significados y sentidos de la realidad circundante en condición de criterios de mediación validadores para las fórmulas de la psicología occidental?

Repasando los tres arquetipos analizados en lo que a la identidad de la filosofía en América Latina se refiere, Santos-Herceg escribe:

El filósofo/Próspero es, en cuanto filósofo europeo, tanto el pensador del poder, del dominio, como el de la liberación. El filósofo/Ariel, por su parte, es tanto el pensador libre como esclavo o, dicho más correctamente, es esclavo en tanto que libre, etéreo, desvinculado de su mundo, de su contexto. El filósofo/Calibán, finalmente, por un lado es el pensador consciente de su dependencia, arraigado en su tierra y comprometido con su liberación, pero que, por otro, tiende a la negación del legado occidental (2010, p. 276)

Esta síntesis vale para el psicólogo latinoamericano, su psicología y el problema de su identidad, alcanzando con poner "psicólogo" allí en donde se habla del "filósofo" o el "pensador",

En conclusión, pero aplicando a la psicología lo que se enuncia respecto de la filosofía: "La filosofía del Nuevo Mundo sería la de los Prósperos y Arieles, la filosofía de Nuestra América sería la de los Calibanes. Habría entonces, al menos dos modos de ser filósofo latinoamericano: habría que moverse entre Ariel y Calibán" (Santos-Herceg, 2010, p. 276).

Esto quiere decir que, más allá de la aparente incompatibilidad que parecería surgir de la lectura propuesta entre la psicología en el Nuevo Mundo y la psicología en Nuestra América como lugares de enunciación y entre Ariel y Calibán como los arquetípicos psicólogos que las sustentan y la dominación y la liberación como sus orientaciones últimas de sentido, se da en América Latina una situación más compleja por la que los lugares de enunciación, los arquetipos y sus orientaciones de sentido "conviven de forma 
conflictiva a ratos, armónicamente en otros momentos" (Santos-Herceg, 2010, p. 277).

Parafraseando finalmente a José Santos-Herceg de cuyo excelente análisis respecto de la identidad de la filosofía en Latinoamérica hemos hecho uso y abuso para nuestro propósito de efectuar un planteo pertinente, válido y vigente sobre "la identidad latinoamericana de la psicología", nos permitimos concluir esta parte de nuestra exposición, señalando: la psicología "en el continente no es la de Próspero, ni la de Ariel o la de Calibán, sino que es la de todos ellos": es una psicología "en la tempestad"13.

\section{Constitución de identidad, constitución de humanidad desde Nuestra América}

El desarrollo hasta aquí efectuado proporciona un cuadro de discernimiento suficiente para cobrar conciencia que el de la identidad latinoamericana de la psicología como el de la identidad latinoamericana de la filosofía son problemas complejos que hacen al conflictivo y nunca acabado proceso de constitución de dichas identidades.

A partir de aquí la identidad de las disciplinas pasará a un segundo plano para poner el primero a la de los sujetos que en América Latina el ejercicio de dichas disciplinas ha venido contribuyendo -intencional o no intencionalmente- a constituir.

Otro filósofo chileno -vale la aclaración, ya que de identidades se trata-, Helio

13 José SantosHerceg cierra sus conclusiones y su libro, escribiendo: "La filosofía en el continente no es la de Próspero, ni la de Ariel o la de Calibán, sino es la de todos ellos: es una "filosofía en la tempestad"." (2010, p. 277). las que como propiamente tales, solamente pueden hacerse efectivas en procesos de auto-reconocimiento y autoposición de los sujetos populares en sus procesos de articulación, organización y activación "desde abajo", habilitando una superación crítica de aquellas "identificaciones". Escribe Gallardo en este sentido: "Moverse contra el carácter del poder autoritario y la sujeción a identificaciones inerciales contiene la autoconstitución de sujetos (autonomía). El concepto contiene un plano abstracto y uno situacional, testimonial y específico: el de la producción y autoproducción de identidades populares efectivas" (2006, p. 115).

Sin pretenderlo, las consideraciones de Gallardo expresan categorialmente el sentido último de las luchas por la independencia de hace doscientos años en la región y por cierto también las luchas a lo largo de los doscientos años transcurridos desde aquella primera independencia con motivación y horizonte de emancipación humana que muy limitadamente se anunciaba en la idea de una nunca alcanzada segunda independencia (Roig, 2003).

Pueden señalarse las "identificaciones inerciales" instituidas por el poder colonial en el marco de su proyecto colonizador, "salvajes" en el caso de los habitantes originarios, "esclavos" en el de los negros cazados en África y esclavizados para aportar en el Nuevo Mundo la fuerza de trabajo que aquellos "salvajes" no tenían capacidad para aportar, "vagos y mal entretenidos" en el caso de los "gauchos" que resultaban de la mezcla de aquellos otros con españoles, portugueses y sus descendientes y que se encontraban en los territorios que hoy ocupan Argentina, el sur de Brasil y Uruguay, por lo que adoptamos a modo de ejemplo una perspectiva regional Estas "identificaciones" procuraban legitimar la dominación colonial sobre estos territorios y sus poblaciones, e internalizadas por éstas últimas, reproducirla y consolidarla. 
Confrontando con el poder colonial y su proyecto colonizador de dominación y "desde abajo" en la relación con el mismo, en el marco de una coyuntura específica del poder real español, que potenció y articuló intereses, tendencias e intenciones que venían cobrando cuerpo entre aquellos diferentes sojuzgados por ese poder colonial, nace el proceso libertador-independentista que en su marcha se va configurando como proyecto alimentado por las emergentes "identidades" productos de la autoestima y el auto-reconocimiento de quienes se sienten ahora "americanos" y no ya europeos de segunda clase, al punto tal de distanciarse críticamente de los "malos europeos" y -el énfasis no es inocente- de los "peores americanos", esto es aquellos nacidos en el Nuevo Mundo pero que se ponen del lado del poder colonial europeo.

Desde esta nueva identidad efectiva y auténtica de "americanos" que se define por la oposición a quienes desde el poder colonial la niegan, los "malos europeos" y los "peores americanos", tal como surge de la letra y el espíritu del Reglamento Provisorio de 1815 de José Artigas "para el fomento de la campaña y seguridad de sus hacendados", se ejerce -con los límites inevitables de lugar y tiempo- una política universalista en los términos de una discriminación positiva al poner en obra la tesis de "que los más infelices sean los más privilegiados", que implica el reconocimiento en términos de dignidad humana de sectores subalternos "negros", "mulatos", "zambos" y "criollos pobres". Tienen lugar así nuevas "identificaciones", ahora desde el poder revolucionario naciente y su identidad "americana", que derivarán en la dialéctica de las "identificaciones inerciales" y las "identidades efectivas" o "auténticas" hasta el presente.

El proceso y proyecto libertadorindependentista, una vez triunfantes las luchas por la independencia se consagran en los nuevos estados por la mediación de las primeras constituciones republicanas del siglo XIX. Éstas implican la consagración de nuevas identidades políticas que promueven nuevas identidades nacionales en territorios en los que, o no había ninguna nación constituida, o en los que la o las existentes eran negadas, arrasadas y también fragmentadas por las fronteras de estas nuevas identidades políticas y sometidas a una cohabitación en la que no obstante ser invisibilizadas y marginalizadas persistieron en su identidad hasta el presente, cuando no fueron objeto de exterminio en la lógica del asesinato fundante de los nacientes estados nacionales americanos. En ese contexto post-independencia se asiste a la emergencia de proyectos y procesos contrapuestos que se disputan la dominación y la hegemonía: el "proyecto conservador" y el "proyecto modernizador" o "civilizador".

El "proyecto conservador" tiene como horizonte reproducir y mantener el orden colonial, pero sin Europa. Ese proyecto, no obstante el "proyecto modernizador" o "civilizador" pueda haber calado hondo al punto tal de poder pensarse como acontece en Uruguay que es el que ha constituido al estado y a la nación, se mantiene vigente hasta el presente a ciento ochenta y dos años de república, si nos remitimos a nuestra primera Constitución uruguaya de 1830. Como lúcidamente observó Martí en 1891 "la colonia continuó viviendo en la república"(2010, p. 12) y podemos decir hoy que continúa viviendo entre nosotros.

El "proyecto modernizador" o "civilizador" se articula sobre la dicotomía "civilización o barbarie" que Domingo Faustino Sarmiento expresara paradigmáticamente en su Facundo de 1845

Los procesos de modernización en el horizonte de ese proyecto suponen dejar atrás y superar por su negación -o su exterminiola "barbarie" propia de lo indígena, lo afro, 
lo mestizo, lo gaucho y también lo ibérico, en la imposición de la "modernización" que remite inicialmente a otros modelos europeos -Francia primero e Inglaterra después- y que ya en el último tercio del siglo XIX comienza a tener a los Estados Unidos de América como su fundamental horizonte de sentido.

El "proyecto colonizador" ibérico en el Nuevo Mundo es en cierto sentido "moderno" pues es plausible la hipótesis que hace del "descubrimiento" de América en 1492 el nacimiento de la modernidad. Aunque es fundamentalmente "anti-moderno" porque procura imponer al Nuevo Mundo estructuras-económicas, políticas, religiosas, culturales, mentales- "premodernas". De esta manera la "anti-modernidad" que establece y procura reproducir y consolidar la "pre-modernidad" en el Nuevo Mundo, se constituye en la condición de posibilidad de desarrollo de la "modernidad" en el Viejo Mundo más allá de las fronteras ibéricas.

El "proyecto conservador" postindependencia, conserva, reproduce y procura consolidar ese sentido "antimoderno" en el Nuevo Mundo, preservando las virtudes de la "pre-modernidad" funcionales a los intereses de quienes lo sustentan y bloqueando de esa manera el libre despliegue de la lógica de la modernidad en estos territorios.

En compulsa con el "proyecto conservador" en lo que éste tiene de "anti-moderno", pero también con las identidades "pre-modernas" (pueblos originarios, africanos esclavizados y sus descendientes, distintos tipos de mestizos) es que el "proyecto modernizador" procura imponer su hegemonía. Más aún, la "pre-modernidad" es una construcción categorial de la "modernidad" en la que se expresa y constituye esa hegemonía: "modernidad" y "pre-modernidad" no designan condiciones diferentes que tienen entre sí una relación simétrica, sino que en tanto ambos conceptos y su relación se acuñan desde la "modernidad" y con el sentido de la afirmación de la misma, "modernidad" como sinónimo de "civilización" es lo superior que como sentido de futuro debe ser afirmado y la "pre-modernidad" como sinónimo de "barbarie" es lo inferior que como mero pasado sin sentido de futuro debe ser negado. En esta perspectiva, hablar de "identidades pre-modernas" es aportar en el marco de lógicas de dominación a la constitución de "identificaciones inerciales". En cambio, hablar de "identidades trans-modernas", habilita transformar "identificaciones inerciales" producidas desde lógicas de dominación de las cuales se tornan reproductoras, en "identidades autónomas" que a través de un auto-conocimiento y auto-reconocimiento despliegan resistencia y activación que irrumpen como ejercicios de liberación.

A diferencia de las "identidades premodernas", las "identidades trans-modernas" no serán ya "identificaciones inerciales" que producidas desde la modernidad, son funcionales a sus lógicas de dominación.

En el sentido en que lo ha señalado el filósofo argentino-mexicano Enrique Dussel desde Nuestra América:

Para la superación de la "Modernidad" (no como Post-modernidad que ataca a la razón en cuanto tal, desde el irracionalismo de la inconmensurabilidad, sino como TransModernidad, que ataca como irracional a la violencia de la Modernidad, en la afirmación de la "razón del Otro"), será necesario negar la negación del mito de la Modernidad. (...) Al negar la inocencia de la "Modernidad" $y$ al afirmar la Alteridad de "el Otro", negado como víctima culpable, permite "des-cubrir" por primera vez la "otra cara" oculta y esencial a la "Modernidad": el mundo periférico colonial, el indio sacrificado, el negro esclavizado, la mujer oprimida, el niño y la cultura popular alienadas, etcétera (las "víctimas" de la "Modernidad") como víctimas de un acto irracional (como contradicción del ideal racional de la misma Modernidad (Dussel, 1992, pp. 246-247) 
Así como la "Trans- Modernidad" se descubre como condición de posibilidad de la "Modernidad" misma, en lugar de quedar reducida como un pasado sin validez ni vigencia que la "Modernidad" ha consagrado en la categoría de "Pre-modernidad"; las "identidades trans-modernas" se descubren como condición de posibilidad de las "identidades modernas" y se ponen en la perspectiva de emanciparse a partir de la superación crítica de las "identificaciones inerciales" en términos de "pre-modernidad" producidas por la "Modernidad" para legitimar y ejercer su dominación.

La "Post-Modernidad", entendida como profundización de la Modernidad en sus ejes nihilista, anti-universalista y anti-emancipatorio ${ }^{14}$, fragmenta las identidades modernas promoviendo nuevas "identificaciones inerciales" desde el poder del Mercado totalizado amparado en su reproducción por el poder del Estado, pero al igual que la "Modernidad" parece encontrar un límite en su capacidad de fragmentación en las identidades "trans-modernas", especialmente en las capacidades de resistencia de las comunidades andino-amazónicas que emergen como antiguas-nuevas identidades a partir de las conmemoraciones de los 500 años del "descubrimiento" de América, emergencias que se proyectan a lo largo de la primera década del siglo XXI, consagrando nuevas Constituciones -Ecuador, 2008 y Bolivia 2009- y definiendo con ellas nuevos estados plurinacionales como identidades políticas emergentes desde la autonomía que la lógica de la "Trans-Modernidad" hasta entonces tejiendo en las sombras, se constituye hoy en presente que interpela crítico-constructivamente a la "Modernidad" y la desafía como horizonte alternativo de futuro.

Estas identidades "trans-modernas" son evidencia empírica de resistencia y emergencia tanto frente al proyecto colonizador como al independentista en sus derivadas como proyectos conservador y modernizador. Ellas aportan un fundamento comunitario al que ha sido conceptualizado por Leopoldo Zea como "proyecto asuntivo"15 y que también podemos caracterizar como "proyecto identitario".

En el universo del discurso letrado en Latinoamérica, expresiones con fuerte capacidad de proyección en el universo discursivo y -eventualmente- por su mediación y la de los letrados que lo asumen, en el universo social, Nuestra América de José Martí de 1891 y Ariel de José Enrique Rodó de 1900-entre otros- no obstante sus diferencias, expresan y promueven el "proyecto asuntivo" con validez y vigencia instituyente ${ }^{16}$ hasta nuestros días más allá de sus limitaciones de época.

Tanto el primero más próximo al sentido de Calibán como el segundo, declaradamente en el sentido de Ariel - sentidos entre los que se define la identidad latinoamericana de la psicología y su capacidad de aporte a la constitución de identidades liberadorasaportan discursivamente tanto a nivel de la enunciación como de lo enunciado a la emergencia identitaria o asuntiva de lo que histórico-culturalmente somos a través del discernimiento crítico de las representaciones alienadas y alienantes de lo que pretendemos ser.

Expresan y orientan la constitución de "identidades auténticas" a través del discernimiento de las "identificaciones inerciales", si nos atenemos a la conceptualización propuesta por Helio Gallardo.

En el contexto actual que se inicia en la década de los '70 del siglo pasado con los cambios en la lógica de acumulación capitalista, la transición de la matriz estado-céntrica a la matriz mercado-céntrica será mediada desde el ejercicio del terrorismo de estado de las 
14 Así entiende la "Post-modernidad" Franz Hinkelammert en "Frente a la cultura de la modernidad: proyecto político y utopía" (Hinkelammert, 1991, pp. 81-101). Hemos hecho nuestro este sentido de

"Post-modernidad" -que entendemos pertinente- en cuanto a que pretendiendo ser una crítica de la modernidad, se configura como una hipercrítica que la profundiza en los sentidos señalados

15 No obstante las interpretaciones y desarrollos que son de la responsabilidad de quien escribe, los proyectos, sus denominaciones y sus relaciones han sido tomados desde el excelente libro del filósofo mexicano Leopoldo Zea

Filosofía de la historia americana (Zea, 1978).

16 Con Mario Sambarino entendemos "la distinción entre lo que en un universo cultural está vigente y

lo que en él es válido", como la que tiene lugar entre "el orden de lo que es según valores" $y$ "el orden de lo que es valioso que sea".

(Sambarino, 1959, pp 229 - 290). A partir de su discernimiento, aportamos la expresión y la perspectiva de la que llamamos "vigencia instituyente". dictaduras militares con el que procurarán destruir las identidades revolucionarias que se venían gestando desde los tempranos ' 60 e imponer "identificaciones inerciales" sobre las que hacer asimilable la destrucción del estado de derecho social y su sustitución por el estado de hecho dictatorial, como mediación para el estado de derecho neoliberal en el que la doctrina de la "seguridad nacional" se convierte en la lógica de funcionamiento del Estado hegemónico planetario, la que declina en los estados periféricos a favor de la doctrina de la "seguridad mercantil" del nuevo estado de derecho posdictadura. Década de los '80 de transición a la democracia y década perdida para el desarrollo en América Latina; década de los 90, omnipresencia de la globalización cuya estrategia se profundiza en las primeras décadas del siglo XXI por las que estamos transitando.

Las "identificaciones inerciales" pasan por la figura del "ciudadano-propietariosúbdito-consumidor-elector" que expresa la hegemonía que hace a la legitimación y reproducción del nuevo orden posautoritario y postransicional ${ }^{17}$.

De acuerdo a los discursos dominantes, parecieran haberse abolido las clases sociales, y con ellas, las identidades de clase.

En lugar de las clases, "sujetos", "actores" y "ciudadanía" pero en la lógica de un capitalismo globalizado, profundizado y totalizado, en que estas pretendidamente nuevas identidades sociales, culturales y políticas, parecieran resultar en última instancia funcionales a la lógica de la modernidad y a la del capitalismo como su lógica económica, por lo que bajo la pretensión de ser identidades emergentes auténticas -desde abajo- podrían resultar resignificadas como identificaciones inerciales --desde arriba- funcionales a la ontología de la modernidad capitalista.
Es por ello tal vez, que las identidades emergentes no logran superar su fragmentación y no pasan de manera dominante del nivel óntico de la crítica. Viejos-nuevos sujetos emergentes como son los pueblos originarios andino-amazónicos a quienes ya nos hemos referido, parecen desplegar una lógica de movimientos comunitarios -en un sentido ancestral de "comunidad" que implica también a los espíritus y a la naturaleza-, tal vez con capacidad de trascender el nivel óntico de la crítica hacia el nivel ontológico y aún al nivel trans-ontológico, por trascender desde su trans-modernidad la lógica de la modernidad la que tal vez no pueden trascender los, así llamados, "nuevos movimientos sociales"18.

Las nuevas identidades auténticas emergentes en nuestra región rioplatense no pueden responder a la lógica de constitución de los viejos-nuevos sujetos andino amazónicos, ni recrear "movimientos comunitarios" transmodernos donde -en todo caso- emergen "movimientos sociales" modernos. No obstante, allí donde la "comunidad" no es un ámbito significativamente vigente de lo humano en términos de lo instituido, es siempre posible la articulación de las identidades sociales emergentes y sus luchas, como forma de superar la fragmentación y procurar evitar la metabolización de las mismas como "identificaciones inerciales" funcionales a la reproducción de la modernidad capitalista, en lugar de serlo a su afirmación y emancipación humana.

De todas maneras, al modo de "la colonia en la república" -si recordamos el pasaje de Martí- o del hombre viejo en el "hombre nuevo" -si pensamos ahora en la perspectiva cristiana de revolución antropológica que como idea-fuerza impregnó en su momento el campo ético-político latinoamericano desde la prédica y la práctica de Ernesto "Che" Guevara; las lógicas de identificación con sus "identidades inerciales" persisten con 
17 Puede hablarse también con sentido de un orden "postransaccional",

si hacemos nuestra la observación realizada en la conferencia de cierre del XII Corredor das Ideias do Cone Sul en São Leopoldo el 14 de septiembre de 2011, respecto a que las Ilamadas "transiciones democráticas" en el Cono Sur de América Latina (Argentina, Brasil, Chile,

Paraguay y Uruguay), fueron de hecho "transacciones" que seguramente muy poco tuvieron de democráticas. $\mathrm{Ni}$ siquiera en lo procedimental se trató del triunfo de los mejores argumentos, sino de la cuota de poder de ejercicio real y virtual de la violencia que logró imponer sus condiciones para, mediante la "transacción" hacer la "transición" y transferir el gobierno con un poder recortado o al menos fuertemente condicionado, a los actores del sistema político.

18 Estas

consideraciones reconocen la impronta del excelente curso que el colega boliviano,

Juan José Bautista dictó para el Núcleo "Pensamiento crítico en América Latina y sujetos colectivos". en Montevideo, junio de 2011, recurrencia en los procesos de afirmación de "identidades auténticas", por lo que la constitución de las mismas y, por su mediación, la constitución de humanidad, es un proceso "conflictivo y nunca acabado"19.

\section{A priori antropológico}

De acuerdo a Arturo Andrés Roig, la filosofía comienza allí donde se ejerce el a priori antropológico, ejercicio que implica la emergente constitución de un sujeto. La tesis de Roig se formula en la perspectiva de fundamentar a la filosofía latinoamericana, sus comienzos y recomienzos que suponen esa emergente afirmación de humanidad.

La filosofía latinoamericana, de acuerdo a Roig, "se ocupa de los modos de objetivación de un sujeto, a través de los cuales se autorreconoce y autoafirma como tal", agregando que tales "modos de objetivación son, por cierto, históricos y no siempre se logra a través de ellos una afirmación de sujetividad plena" (Roig, 1993, p. 105).

Propongo ahora trasladar esa tesis a nuestra cuestión de la identidad latinoamericana de la psicología y enunciar que la Psicología Latinoamericana se ocupa de los modos de subjetivación de un sujeto, a través de los cuales se autorreconoce y autoafirma como tal. Podemos agregar con Roig, pero ahora para la sujetividad a la que la Psicología Latinoamericana procura contribuir en sus procesos de autorreconocimiento y autoafirmación, que esos modos de subjetivación son, por cierto históricos y no siempre se logra a través de ellos una afirmación de subjetividad plena.

Ahora no nos interesará centralmente la cuestión de la constitución de la Filosofía Latinoamericana a través de sus comienzos y recomienzos, ni tampoco la de la Psicología Latinoamericana en análogas emergencias de las que la de estos tres últimos días puede ser una muy significativa Nos centraremos en la constitución del sujeto, su identidad y su humanidad, tanto en sus modos de objetivación que hacen a su sujetividad -a la que aportará la Filosofía Latinoamericanacomo en los de su subjetivación que configuran su subjetividad -en los que la Psicología Latinoamericana contribuirá significativamente- en el ejercicio del a priori antropológico.

El ejercicio del a priori antropológico, más que un acto puntual, es un proceso de carácter a posteriori respecto de procesos, prácticas o relaciones que impliquen, negación, invisibilización o sojuzgamiento de ese sujeto.

En el marco de un sistema, de relaciones sociales, de lógicas institucionales o de prácticas puntuales en América Latina que con efectos de negación, invisibilización y sojuzgamiento producen "identidades inerciales" que hacen a la heteronomía de los modos de objetivación y de subjetivación de los sujetos, se dan las condiciones para que pueda acaecer la emergencia del a priori antropológico y con ella la constitución del sujeto en términos de una "identidad auténtica" que en sus sentidos de afirmación, visibilización y liberación, la Filosofía Latinoamericana y la Psicología Latinoamericana pueden acompañar.

El "a priori" antropológico" es caracterizado como "ponernos a nosotros mismos como valiosos" $\mathrm{y}$ "tener como valioso conocernos por nosotros mismos" (Roig, 1981, p. 9-17).

\section{Expresa Roig:}

"Aquella afirmación de subjetividad es condicionante, pero inevitablemente también condicionada. Hacemos nuestras las circunstancias, mas, también ellas nos hacen. Debido a esto la historia de aquél acto de afirmación nos muestra un elevado grado de contingencia y el desarrollo del proceso de autorreconocimiento 
y autoposición, muestra comienzos y recomienzos.

Mas, el valorar un momento y proponer un comienzo implica una prospectividad, una posición proyectiva desde la cual no solo se mira con una actitud constructiva hacia delante, sino que se mira hacia atrás con igual signo. Se trata de una objetividad que no renuncia al punto de vista inevitablemente subjetivo. Aquí "subjetividad" y "sujetividad" se identifican. Ponemos en juego un derecho respecto de nuestro pasado, el de medirlo respecto de un futuro vivido desde este presente. De ahí la selectividad inevitable en la determinación acerca de lo que sea "hecho histórico" o no para ese sujeto y también la necesidad de fijar el criterio desde el cual se pone en ejercicio.

De este modo surge un tipo de narratividad que es proyectivo, es decir que no se queda en lo constatativo y que, todavía más, reviste pretensión de performatividad. Vale decir, que su enunciado describe una determinada acción del locutor y su enunciación tiene la pretensión de ser el equivalente al cumplimiento de la misma" (Roig, 1993, pp. 105-106) ${ }^{20}$.

en el conjunto de mis textos y exposiciones, dada su adecuación a la idea que quiero transmitir, ahora para la problemática constitución de las que discerniéndolas de las

"identificaciones inerciales", he llamado "identidades auténticas", proceso que obliga a que ese discernimiento sea permanente, dado el carácter recidivante de "las identificaciones inerciales", me inspiro en el título que el filósofo germanochileno Norbert Lechner acuñó para referirse a la construcción del orden democrático (Lechner, 1986).

\section{Autoconocimiento y reconocimiento en Nuestra América}

Del mismo modo que hemos afirmado que la construcción de la memoria, entendida como condición de posibilidad para la constitución de identidades auténticas, supone la interlocución con una historia que en el horizonte de ese proceso "conflictivo y nunca acabado" de constitución, sea capaz de discernir hechos y procesos históricos a través de la desnaturalización de los mismos por su historización, afirmaremos ahora que en la perspectiva de constitución de dichas "identidades auténticas" en Nuestra América, es fundamental el "autoconocimiento", esto es, el conocimiento de nosotros mismos por nosotros mismos. Afirmaremos también que este "autoconocimiento" en tanto que somos un "nosotros" en proceso de constitución "conflictivo y nunca acabado", implica el "reconocimiento" y el respeto en términos de igual dignidad de las alteridades y diferencias que lo constituyen, aunque también el señalamiento crítico de aquellas cuya posición -política, social, económica, cultural- implica ejercicio -sea intencional o no intencional- de asimetrías y por lo tanto, de dominación.

El horizonte de constitución de un "nosotros" que pueda superar las lógicas de dominación implícitas en las "identificaciones inerciales", implica que la afirmación de la buena vida o de la humanidad de unos, no implique la negación de la de otros.

Este criterio vale para "nosotros los latinoamericanos" pero también para cualquier otro nosotros que al interior del mismo o en relación con él, pueda reconocerse.

La prioridad para "nosotros" es conocernos para asumirnos y proyectarnos con discernimiento. Este conocimiento, que es "autoconocimiento" no ensimismado, implica discernir y elaborar 
el marco categorial que al desprenderse de nuestras formas características de sentir, pensar y actuar, haga posible un reconocimiento de nuestras diferencias sin que ello implique convalidación de las asimetrías, que es condición para relaciones horizontales de "reconocimiento" con otros "nosotros".

Pero el "reconocimiento" de nuestra humanidad, depende fundamentalmente de que al interior de "nosotros mismos" tengamos la capacidad de discernir los inerciales y recurrentes espacios de inhumanidad que nos acompañan para superarlos.

Afirmar la humanidad supone a partir de nuestro autoconocimiento la transformación de nuestra humanidad a los efectos de que nuestra afirmación no implique la deshumanización de los otros.

Para transformar la humanidad a los efectos de que el reconocimiento no sea solamente una retórica para convalidar la deshumanización y el sometimiento, -y esto vale para las relaciones al interior de cada "nosotros" como para las relaciones entre los diversos "nosotros" existentes o posibles, se trata de echar por tierra "todas las relaciones en las cuales el hombre es un ser envilecido, humillado, abandonado, despreciado" (Marx, 1968, p.15).

Sin el cumplimiento de este imperativo categórico en la producción y reproducción de la cotidianidad, las luchas por la identidad y el reconocimiento no podrán ir más allá de una retórica de la afirmación de lo humano sin exclusiones, y correrán el riesgo de ser discursos funcionales a la reproducción de diversas exclusiones del ámbito de lo humano que se pretende legítimamente universal.
20 Arturo Andrés Roig, nacido en Mendoza en 1922 falleció el 30 de abril de 2012, dos días después de brindada esta conferencia. La presencia de su pensamiento filosófico en nuestro pretendido aporte a la construcción de la identidad latinoamericana de la psicología, atraviesa el conjunto del mismo. Esta larga cita testimonia el valiosísimo aporte de su pensamiento para nuestro asunto, sin mediaciones que lo opacarían. 
Yamandú Acosta

Universidad de la República, Montevideo, Uruguay.

E-mail: yamacoro@adinet.com.uy

Endereço para envio de correspondência:

Dr. Pablo de María 1297, Apto. 801, Montevideo, URUGUAY. 


\section{Referências}

Dussel, E. (1992), 1492. El encubrimiento del otro. El origen del mito de la modernidad, Santafé de Bogotá: Editorial Antropos.

Gallardo, H. (2006), Siglo XXI. Producir un mundo. San José, Costa Rica: Editorial Arlekín.

Hegel, G. F. (1968). Filosofía del Derecho. Buenos Aires: Editorial Claridad

Hinkelammert, F. J. (1991). La fe de Abraham y el Edipo occidental. (2a. ed.). San José, Costa Rica: DEI.

Hobbes, T. (1994), Leviatán. Barcelona: Altaya.

Kant, I. (1967), Crítica de la razón pura. (Tomo I, 5a. ed.). Buenos Aires: Losada

Lechner, N. (1986). La conflictiva y nunca acabada construcción del orden deseado, Madrid: CIS-Siglo XXI.

Martí, J. (2010), Nuestra América. La Habana: Centro de Estudios Martianos (Edición Crítica, Alba Bicentenario Ensayo).

Marx, C. (1955), "Prólogo de la Contribución a la Crítica de la Economía Política". In C. Marx, \& F. Engels. Obras escogidas. (Tomo I, pp. 339-343). Moscú: Editorial Progreso.

Marx, C. (1968). "Introducción para la Crítica de la Filosofía del Derecho de Hegel". In G.F. Hegel. Filosofía del Derecho. (pp. 7-22). Buenos Aires: Editorial Claridad
Roig, A. A. (1981). Teoría y crítica del pensamiento latinoamericano México: FCE.

Roig, A. A. (1993). Rostro y filosofía de América Latina. Mendoza, Argentina: EDIUNC

Roig, A. A. (2003). Necesidad de una segunda independencia. Río Cuarto, Argentina: Universidad Nacional de Río Cuarto.

Sambarino, M. (1959), Investigaciones sobre la estructura aporético - dialéctica de la eticidad. Montivideo: Facultad de Humanidades y Ciencias, Universidad de la República

Sambarino, M. (1976), "La función socio-cultural de la filosofía en Latinoamérica". In La filosofía actual en América Latina. (pp. 165-181). Grijalbo, México.

Santos-herceg, J. (2010), Conflicto de Representaciones. América Latina como lugar para la filosofía, Chile: FCE.

Zea, L. (1978). Filosofía de la historia americana. México: FCE. 